\title{
Biotechnological production of carotenoids by yeasts: an overview
}

\author{
Luis Carlos Mata-Gómez ${ }^{1}$, Julio César Montañez ${ }^{2}$, Alejandro Méndez-Zavala² and Cristóbal Noé Aguilar ${ }^{3}$
}

\begin{abstract}
Nowadays, carotenoids are valuable molecules in different industries such as chemical, pharmaceutical, poultry, food and cosmetics. These pigments not only can act as vitamin A precursors, but also they have coloring and antioxidant properties, which have attracted the attention of the industries and researchers. The carotenoid production through chemical synthesis or extraction from plants is limited by low yields that results in high production costs. This leads to research of microbial production of carotenoids, as an alternative that has shown better yields than other aforementioned. In addition, the microbial production of carotenoids could be a better option about costs, looking for alternatives like the use of low-cost substrates as agro-industrials wastes. Yeasts have demonstrated to be carotenoid producer showing an important growing capacity in several agro-industrial wastes producing high levels of carotenoids. Agro-industrial wastes provide carbon and nitrogen source necessary, and others elements to carry out the microbial metabolism diminishing the production costs and avoiding pollution from these agro-industrial wastes to the environmental. Herein, we discuss the general and applied concepts regarding yeasts carotenoid production and the factors influencing carotenogenesis using agro-industrial wastes as low-cost substrates.
\end{abstract}

Keywords: Pigments, Yeast, Agroindustrial wastes

\section{Introduction}

Carotenoids belong to the most important components in foods. They are natural colorants, as yellow to red colors, so they have great influence on the acceptability of many foods. Moreover, some carotenoids are precursors of vitamin $\mathrm{A}$; in terms of human health, they are among the bioactive phytochemicals credited that reduce risks for degenerative diseases such as cancer, cardiovascular diseases, macular degeneration and cataract [1]. Carotenoids are naturally occurring lipid-soluble pigments, the majority being $\mathrm{C}_{40}$ terpenoids, which act as membrane-protective antioxidants scavenging $\mathrm{O}_{2}$ and peroxyl radicals; their antioxidant ability is apparently attributed to their structure. Carotenoids pigments occur universally in photosynthetic systems of higher plants, algae and phototrophic bacteria. On the other hand, in non-photosynthetic organisms, carotenoids are important in protecting against photooxidative damage. Thus, many non-phototrophic bacteria

\footnotetext{
* Correspondence: julio.montanez@uadec.edu.mx

${ }^{2}$ Chemical Engineering Department, School of Chemistry, Universidad

Autónoma de Coahuila, Saltillo, Mexico

Full list of author information is available at the end of the article
}

and fungi rely on carotenoids for protection when growing on conditions where light and air are abundant [2].

Interest in carotenoids has increased considerably, mainly due to the benefits to human health and also to the growth of certain areas such as agriculture, especially aquaculture and poultry industry [3], Britton, nutritional supplements [4] food industry where they are used as coloring agents for cooked sausages, soft drinks, baked goods and pharmaceutical as additive to cosmetics $[5,6]$. Carotenoids market has resulted interesting in 2010 estimated at nearly $\$ 1.2$ billion, but the expectations for 2018 are increasing considerably supposing to reach $\$ 1.4$ billion with a compound annual growth rate of 2.3 [7].

\section{Classification and nomenclature}

Carotenoids are terpenoid pigments of 40 carbon atoms derived biosynthetically from two units of geranylgeranyl transferase pyrophosphate, they are soluble principally in nonpolar solvents. These pigments are grouped in carotenes and xanthophylls. Some carotenes only have carbon and hydrogen on their chemical structure such as $\beta$-carotene and Torulene; while xanthophylls also

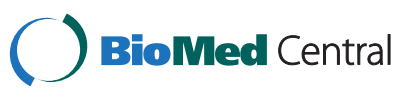


contain oxygen such as Astaxanthin and Canthaxanthin. Chemical structures of some carotenes are shown in Figure 1 [8].

Generally, carotenoids are denominated according to structural variations of lateral rings, specially the double bond position. In general, carotene is used for the suffix carotene; and xanthophylls for the suffix ina [2].

Some of the microbial carotenoids produced by yeasts reported are:

- $\beta$-carotene $\left(\beta-\beta^{\prime}\right.$-carotene) (Figure 1a) this molecule has been used as food colorant or as a food supplement acting as provitamin $\mathrm{A}$, in a concentration ranges from 2 to $50 \mathrm{ppm}$. It also is added to juices and drinks formulations (hydrophilic matrices) and others (lipophilic matrices) such as butter, margarine and cheese [9].

- Torulene (3', 4'-didehydro - $\beta, \psi$-carotene) (Figure 1b) owns 13 conjugated double bonds, and has an attractive color. The antioxidant properties of torulene are attributed to its conjugated double bond system; in fact Torulene has more antioxidant efficiency than $\beta$ -carotene, which presents less double bond on its chemical structure than torulene $[10,11]$.

- Astaxanthin (3, 3'-dihydroxy- $\beta, \beta$-carotene -4, $4^{\prime}$-dione) (Figure 1c) is a red pigment that causes coloration in marine invertebrates, fish and birds. Likewise carotenes described before it is applied as a colorant to confer the typical pink-red color of farmed salmon, trout and shrimp [12,13].

- Canthaxanthin ( $\beta$ - $\beta^{\prime}$-carotene-4, $4^{\prime}$-dione) is a cosmopolitan keto-carotene that is of interest by food and cosmetic industries, mainly [14].

\section{Biological properties of carotenoids}

Commonly, carotenoids are distinguished as a vitamin A precursor, for this reason they are known as high-value nutritional molecules. The low intake of vitamin A is a nutritional problem in underdeveloped areas of the world.
Its consequences are deficiency on tears production, blindness, principally in children, plus premature death [15]. Thus, vitamin A also shows other systemic functions maintaining like growth and reproductive efficiency, besides maintainings the epithelial tissue $[9,16,17]$. The carotenoid molecule provides antioxidant properties when it presents a cyclic structure joined to its carbons chain [18].

The antioxidant features of these compounds does not depends on its pro-vitamin A activity, because its capacity to attract oxygen with its double bond [17-20]. Apart of the properties described above, carotenoids also promote healthy effects including: improvement of immunity and diminishing in the risk of degenerative diseases such as cancer, heart diseases, cataract and macular degeneration [21-23]. Carotenoids intake, can prevent photoaging and sun burning on skin, but they must be ingested during weeks as to increase their levels in blood, and consequently increase protection [18].

Natural carotenoids have similar molecular structure than synthetics, but natural carotenoids differ on molecular structure providing major benefits to health. Industrial production of natural carotenoids can be carried out through to i) biotechnological processes using filamentous fungi, yeasts, bacteria or microalgae, and ii) solid-liquid extraction from plants. It has been reported that in the worldwide production of $\beta$-carotene only the $2 \%$ is from natural sources [24].

\section{Microbial carotenoid production}

The commercial carotenoids are obtained by extraction from vegetables [25] and chemical synthesis [26]. However, in the case of production and marketing of several colorants from plants origin there are some problems regarding seasonal and geographic variability that cannot be controlled [27]. Own its part; the chemical synthesis generates hazardous wastes that can affect the environment. Unlike these traditional methods, the microbial production of carotenoids shows great interest and safety to use. Microbial production has the advantage to

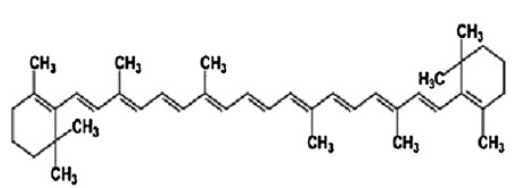

a

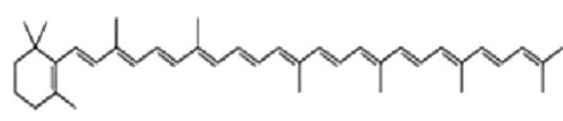

b

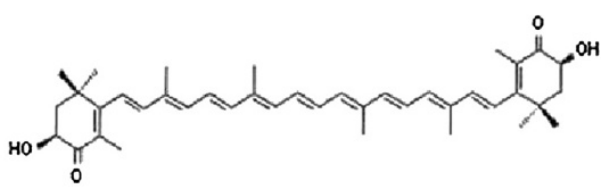

C

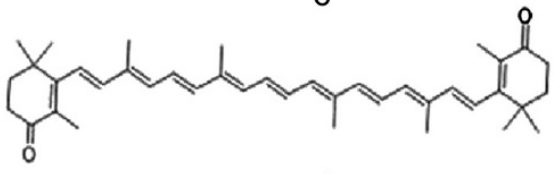

d

Figure 1 Molecules of carotenes: a) $\beta$-carotene, b) Torulene; xanthophylls: c) Astaxanthin, d) Canthaxanthin. 
use low-cost substrates, resulting in lower costs of production. This explains the increasing interest in production of microbial carotenoids as substitutes for synthetic carotenoids used as colorants in food [3]. Thus, microbial synthesis offers a promising alternative for carotenoids production.

Carotenoids are widely distributed in microorganisms including bacteria, yeast, fungus and algae. Commercial production of microbial carotenoids is highly efficient because they can be easily managed during the processes [28].

Several reports in literature have described carotenoids production by fungus. Papaioannou and LiakopolouKyriakides [29], reported the use of Blakeslea trispora to produce $\beta$-carotene. Another mould, Phycomyces blakesleeanus is also known for its capacity to produces $\beta$ carotene at industrial scale, has been studied by Almeida and Cerda-Olmedo [30]. Studies carried out by CerdaOlmedo [31] demonstrated that the most productivity strains of Phycomyces $b$. reach their maximum carotenogenic potential on systems without agitation; unlike to $B$. trispora strains. Also different authors have described the production of carotenoids by yeasts like Rhodotorula spp. This yeast, widely distributed in nature, can biosynthesize specific carotenoids such as $\beta$-carotene, torulene and torularhodin, in different proportions [32,33]. The production of carotenoids by genus Rhodotorula varies between species, and is affected by medium constituents and environmental conditions. The amount of carotenoids produced by this genus can be classified as low (less than $100 \mu \mathrm{g} \mathrm{g}^{-1}$ ), medium (101 to $505 \mu \mathrm{g} \mathrm{g}^{-1}$ ) and high (more than $500 \mu \mathrm{g} \mathrm{g}^{-1}$ ) as reported by many others [34-38]. Many studies of astaxanthin production have been published using the yeast Xanthophyllomyces dendrorhous developing reliable biotechnological processes. So, yeasts are reliable microorganisms to produce carotenoids. Bacteria have been reported as producers of cantaxanthin mainly, a carotenoid of interest in poultry, fishery, cosmetics, medicine, pharmaceuticals and food industries. Among the most studied carotenoids producers bacteria are Corynebacterium michiganense, Micrococcus roseus, Brevibacterium spp., Bradyrhizobium spp., Gordonia jacobaea and Dietzia natronolimnaea [39].

Microalgae belonging to Chlorophyceae group are the most recognized as producers of important commercial carotenoids, highlighting the genus of Chlorella, Dunaliella, and Haematococcus. These microalgae are able to produce lutein, $\beta$-carotene and astaxanthin [40]. Specifically the production of astaxanthin by Haematococcus pluvialis requires certain conditions during its cultivation, because it changes its structure during the growth cycle [41,42]. This means that the physical properties and nutrient requirements of the algae change during de culture process, altering the optimal conditions for growth and carotenoid production [43].
In general there is a vast of microorganisms that can biosynthesize carotenoids; however still lack of information is missing regarding strategies to maximize production at industrial scale. Nevertheless, although there are many strategies for stimulation of carotene biosynthetic pathways in yeasts, attention is still focused on unexplored habitats for selection of hyper-producing strains, which is the important step toward the design and optimization of biotechnological process for pigment formation $[1,44]$. Synthesis of important natural carotenoid by yeasts leads to consider them to industrial scale [45].

Also to knowledge of metabolic engineering tools to manipulate the biosynthetic pathway for carotenoid production by yeasts is very important. In 1964 Simpson et al. [46] described a possible biosynthetic pathway for carotenoid synthesis. Later, Goodwin [47] revised the general pathways for biosynthesis of carotenoid by yeasts and concluded that the carotenoid biosynthesis pathway involves three general steps:

1) Synthesis begins with conversion of acetyl CoA to 3-hidroxy-3-methyl glutaryl-CoA (HMG-CoA), catalyzed by HMG-CoA synthase. Then, HMG-CoA is converted in mevalonic acid (MVA), this is the first precursor of terpenoid biosynthetic pathway. MVA is phosphorylated by MVA kinase and decarboxylation; into isopentenyl pyrophosphate (IPP).

2) IPP is isomerized to dimethyllayl pyrophosphate (DMAPP) with the addition of three IPP molecules to DMAPP, catalyzed by prenyl transferase into geranyl geranyl pyrophosphate (GGPP). Condensation of two molecules of GGPP produces the phytoene (the first $\mathrm{C}_{40}$ carotene of the pathway); which is subsequently desaturated to form lycopene.

3) Many cyclic carotenoids are derived from lycopene, as $\beta$-carotene, $\gamma$-carotene, Torulene, Torularhodin and Astaxanthin when it undergoes many reactions.

As it has been mentioned $\beta$-carotene can be produced by many microorganisms. Focusing on yeasts of the genus Rhodotorula, there are some species such as Rhodotorula glutinis, Rhodotorula minuta, Rhodotorula mucilaginosa, Rhodotorula acheniorum and Rhodotorula graminis recognized as carotenoid producers. Also other yeast as Sporobolomyces roseus, Sporobolomyces salmonicolor and Sporobolomyces patagonicus are carotenoids producers. These yeasts are known as the most producers of $\beta$-carotene, therefore they are the most studied. Besides $\beta$-carotene these yeasts produces other carotenoids identified as Torulene, Torularodine, and $\gamma$ -carotene [1,32,48,49].

The culture conditions, such as carbon and nitrogen sources influence the carotenoid profiles in yeasts as $R$. 
glutinis, the main carotenoid produced likely is $\beta$ -carotene (about $25-43 \%$ of total carotenoids) and Torulene, the second largest (about $28-30 \%$ of total carotenoid) [16] $R$. glutinis has been used to produce $\beta$ -carotene cultivated in glucose, whey, sugar cane (Saccharum spp.) molasses supplemented with yeast extract, and fermented radish (Raphanus sativus) brine [41].

Recently the worldwide production of $\beta$-carotene has increased due to the widely applications in different areas. $\beta$-carotene is a carotenoid known as the main source of pro-vitamin A, which is used in the treatment of medical diseases, and also used as food colorant among other applications. $\beta$-carotene as a high value compound showed a global market of \$ 233 million dollars in 2010, and is expected to reach $\$ 309$ million by 2018 with an annual growth rate of $3.6 \%$ [8]. Other carotenoid with high added value is astaxanthin; it is mainly produced by the yeast Xanthophyllomyces denrorhous (Phaffia rhodozyma). Astaxanthin is a powerful antioxidant that has attracted industrial interest for the application in aquaculture, chemical, pharmaceutical, and alimentary industries [50-55]. Astaxanthin is the third most important carotenoid economically after $\beta$ -carotene and lutein. Astaxanthin market reached the $29 \%$ of total carotenoid sales with a global market size of \$ 225 million dollars, estimating increase to $\$ 253$ million by 2018 , approximately [8].

\section{Factors influencing the production of carotenoid in yeasts} Recently, researchers have been interested on biotechnological processes to obtain high added value metabolites like carotenoids, due to the benefits that they offer to different industrial areas such as pharmaceutical, medical, and food and beverages. Therefore the production of microbial carotenoids at industrial scale must look for low-cost processes, high yields, and environmental friendly. However, the biotechnological synthesis of carotenoids is influenced by many factors involved in the processes that can affect the yields and operation costs. Some of these important factors to consider are:

- Carbon source is the most studied parameter to influence carotenogenesis. Metabolism of yeasts acts depending on the kind of carbon source in the medium. Glucose and other fermentable sugars are metabolized by the glycolytic pathway, and then an alcoholic fermentation, even with oxygen [14]. On the other hand, the carbon sources no fermentable as ethanol and succinate is carried out through acetyl-CoA oxidation to enter the citric acid cycle. Many authors have mentioned that carbon sources as ethanol provoke an increase in the pigments synthesis [12,56-58].
- Light is an important factor to considerate during the production of microbial carotenoids; hence, it improves carotenogenesis [59]. Microorganisms need to prevent themselves from the light that causes damage, and carotenogenesis is a photoprotective mechanism [60-62]. Carotenoid production is affected positively by white light, and carotenoid concentration depends of the microorganism. In addition, carotenoid production is associated to the increasing of the enzymes activity involved in carotenoid biosynthesis [63]. Moliné et al. [49] studied the relationship between carotenoids and ergosterol and cell UV-light resistance in strains of $R$. mucilaginosa, and reported that the hyper-pigmented strains showed enhanced survival (250\%). They also indicated that higher production of torularhodin improves UV-light survival in yeasts. On the other hand, Yen and Zhang [64] evaluated the $\beta$-carotene productivity in a batch reactor with two LED (light emitting diode) lamps resulting in a $\beta$-carotene concentration $24.6 \mu \mathrm{g} \mathrm{g}^{-1}$; whereas without light the $\beta$-carotene concentration was found to be $14.69 \mu \mathrm{g} \mathrm{g}^{-1}$.

- Temperature is another parameter to take into account in carotenoid production by yeasts, it affects the cell growing and metabolite production, it acts changing the biosynthetic pathways, including the carotenogenesis. The effect of temperature depends on the microorganism and the quantity of product [56,65-69]. Malisorn and Suntornsuk [70] optimized the temperature effect over carotenoid and biomass production in Rhodotorula glutinis, reporting at 29 and $30^{\circ} \mathrm{C}$ the maximum production, respectively.

According to Hayman et al. [71], temperature effect regulates the enzyme concentration involved in the carotenoid production, and therefore the carotenoid levels in microorganisms are controlled.

- Aeration is another important parameter, due to carotenogenesis is an aerobic process, and the airflow rate in the yeast culture is an essential factor to the substrate assimilation for the growth rate, cell mass and carotenogenesis. Also, decreasing oxygen levels influences the production of carotenes or xantophylls, due to oxidation of carotenes in Astaxanthin, Cantaxanthin and others [12]. The effect of aeration depends on the species of the microorganism [72-87]. Saenge et al. [44] examined the effects of aeration rate on cell growth, lipid yield, carotenoids production and glycerol consumption. It was noticed that the aeration rate had a significant effect on biomass and lipids production, when it was increased from 0 to $2 \mathrm{vvm}$, the biomass and lipid yield were the highest at 8.17 and $4.32 \mathrm{~g} \mathrm{~L}^{-1}$, respectively. 
- Metal ions and salts (Ba, Fe, Mg, Ca, Zn and Co) have also been demonstrated to be stimulants carotenoids production by $R$. glutinis [88]. Otherwise, Buzzini et al. [89] reported that certain trace elements have shown a selective influence on the carotenoid profile in $R$. graminis. In the case of $\mathrm{Al}^{3+}$ and $\mathrm{Zn}^{2+}$ a stimulatory effect on $\beta$-carotene and $\gamma$ - carotene production was observed, while $\mathrm{Zn}^{2}$ ${ }^{+}$and $\mathrm{Mn}^{2+}$ showed inhibitory effect on torulene and torularhodin production. The effect of trace elements mentioned is attributed to the activation of specific carotenogenic enzymes [71].

- The solvents and chemical or natural agents have been studied regarding their effect on carotenogenesis. Kim et al. [90] reported that cell mass and astaxanthin production is stimulated by the addition of ethanol $\left(10 \mathrm{~g} \mathrm{~L}^{-1}\right)$ and acetic acid $\left(5 \mathrm{~g} \mathrm{~L}^{-1}\right)$ to a fed-batch culture of $P$. rhodozyma that resulted $45.62 \mathrm{mg} \mathrm{L}^{-1}$ and $43.87 \mathrm{mg} \mathrm{L}^{-1}$ of carotenoids concentration, respectively. Similarly, Gu et al. [58] reported increased carotenoid production (from 1.65 mg carotenoids $\mathrm{g}^{-1}$ cells to $2.65 \mathrm{mg}$ carotenoids $\mathrm{g}^{-1}$ cells) upon addition of $0.2 \%(\mathrm{v} / \mathrm{v})$ ethanol to cultures of the yeast $X$. dendrorhus.

The culture conditions, such as carbon and nitrogen sources influence the carotenoid profiles in yeasts as $R$. glutinis, the main carotenoid produced likely is $\beta$-carotene (about $25-43 \%$ of total carotenoids) and Torulene, the second largest (about $28-30 \%$ of total carotenoid) [16] R. glutinis has been used to produce $\beta$-carotene cultivated in glucose, whey, sugar cane (Saccharum spp.) molasses supplemented with yeast extract, and fermented radish (Raphanus sativus) brine [46]. An alternative to decrease the industrial operation costs during the synthesis of microbial carotenoids is the use of agro-industrial wastes as substrates.

\section{Low-cost substrates}

Carotenoid pigments synthesis in yeasts starts at the late logarithmic phase continuing in the stationary phase $[82,91,92]$, the presence of a reliable carbon source is important for carotenoid biosynthesis during the stationary phase. Yeasts can synthesize carotenoids when cultivated in commercial medium, containing various refined carbon sources, such as glucose $[34,66,70,74,79,86,87,92-96]$, xylose [97], cellobiose [96], sucrose [98,99], glycerol [79] and sorbitol $[91,96]$, nevertheless these type of medium represents high costs. As a result, studies on carotenogenesis have led to find out low-cost substrate as alternative to reduce production costs. Therefore, there have been a growing interest in the use of natural substrates as carbon sources such as grape juice [65,100]; grape must [101,102]; peat extract and peat hydrolyzate $[65,82,103,104]$; date juice of Yucca filifera [81], hydrolyzed mustard waste isolates [105], hemicellulosic hydrolyzates of eucalyptus globules wood [106,107], hydrolyzed mung bean waste flour [107], sugar cane juice [80,108,109], sugar cane and sugar-beet molasses [42,67,110], corn syrup [45,77], corn hydrolyzate $[111,112]$, milk whey $[67,71,72,75,78]$. These by-products from industrial processes are pollutants to the environmental and their treatment represents high costs. In recent years, raw materials and agro-industrial wastes origin have been proposed as low-cost alternative carbohydrate sources. On this regard, chicken feathers and sweet potato have been introduced as nitrogen and carbon sources [113], respectively to produce carotenoid, and also minimizing environmental and energetic problems related to their disposal [114]. Many investigations have been performed to diminish the costs and optimize the carotenoid production; and factors such as carbon and nitrogen source are very important to consider on the selection of agro-industrial waste as substrates [115].

A wide spread natural substrate is milk whey; it contains lactose, proteins and minerals, principally. Biological wastewater treatment technologies can assist in safe disposal of whey within environmental specifications, but these are expensive [116] becoming an attractive low-cost substrate for microbial production of carotenoids. Carotenoid production by lactose-negative yeasts in whey ultrafiltrate could be carried out by enzymatic hydrolysis of lactose to single sugars (glucose and galactose), thus providing the method of cocultivation with lactose-positive yeasts, producers of $\beta$ galactosidase [78], or modifying culture conditions under which lactose is hydrolyzed into carbon sources easily assimilated by the yeast $[71,72,75]$. Nasrabadi and Razavi [117] reported a carotenoid production of a lactose positive mutant strain ( $R$. acheniorum), finding a yield of $262.12 \pm 1.01 \mathrm{mg} \mathrm{L}^{-1}$ of $\beta$-carotene.

Aksu and Eren [68] reported that the addition of cottonseed oil to the $R$. mucilaginosa culture medium increased the production of total carotenoids with yield of $57.6 \mathrm{mg} \mathrm{L}^{-1}$ of carotenoids, while a concentration of 39.5 $\mathrm{mg} \mathrm{L}^{-1}$ was reached without the addition of activators. Table 1 presents the most recent agro-industrial residues used as substrate to microbial carotenoid production, and the carotenoid quantities obtained. Production of carotenoid with agro-industrial wastes depends on the kind carbon and nitrogen source, minerals and other components, as well as the quantities of each one. The composition of these materials is very important to define the preparation of culture media to improve the carotenogenesis on microorganisms.

\section{Biotechnological processes}

Nowadays, the importance of biotechnological processes has increased due to benefits that they provide such as 
Table 1 Recent researches of use of agro-industrial wastes as substrates to yeasts carotenoid production

\begin{tabular}{lccc}
\hline Authors & Substrate & Yeast & Yield \\
\hline Marova et al., [116] & Whey & R. glutinis & $46 \mathrm{mg} \mathrm{L}^{-1}$ of $\beta$-carotene \\
Marova et al., [116] & Potato medium & R. mucilaginosa & $56 \mathrm{mg} \mathrm{L}^{-1}$ of $\beta$-carotene \\
Saenge et al., [44] & Crude glycerol & R. glutinis & $135.2 \mathrm{mg} \mathrm{L}^{-1}$ of carotenoids \\
Taskin et al., [118] & Chicken feathers & R. glutinis & $92 \mathrm{mg} \mathrm{L}^{-1}$ of carotenoids \\
Nasrabadi and Razavi, [115] & Whey ultrafiltrate & R. acheniorum & $262 \mathrm{mg} \mathrm{L}^{-1} \beta$-carotene \\
Valduga et al., [119] & Whey & S. salmonicolor & $590.4 \mu g \mathrm{~L}^{-1}$ of carotenoids \\
Malisorn and Suntornsuk [120] & R. glutinis & $19 \mu \mathrm{L} \mathrm{L}^{-1} \mathrm{~h}^{-1}$ of $\beta$-carotene \\
Malisorn and Suntornsuk [70] & Fermented radish brine & R. glutinis & $201 \mu \mathrm{L} \mathrm{L}^{-1}$ of $\beta$-carotene \\
Tinoi et al., [32] & Fermented radish brine & R. glutinis & $3.48 \mathrm{mg} \mathrm{L}^{-1}$ of carotenoids \\
Frengova et al., [72,73] & Mung bean waste flour and sweet potato extract & R. glutinis & $10.2 \mathrm{mg} \mathrm{L} \mathrm{L}^{-1}$ of carotenoids \\
\hline
\end{tabular}

high yields, low costs and less waste disposals. These benefits are dependent on nutrients and the culture conditions such as inoculum size, $\mathrm{pH}$, aeration, agitation, and others.

To design a biotechnological process, many factors must be taken in consideration such as bioreactor design, raw materials, the microorganism or enzyme, type of fermentation (batch, feed-batch or continuous). These features play a very important role to achieve the desired yields of a target metabolite [121]. The configuration and volume of the bioreactor is an important factor to consider in the microbial production of carotenoids. Several investigations using yeast for the production of microbial carotenoids in stirred tank bioreactors have been published (Table 2). A fully functional bioreactor offers advantages such as perfect integration of several components, ensuring that cultures will reach the desired productivity of microbial pigments or other microbial compounds, through an efficient and rigorous control of some parameters such as temperature, agitation, aeration, $\mathrm{pH}$ and dissolved oxygen among others.

Figure 2 illustrates a scheme of a general biotechnological process where the bioreactor is the central part of the process.

Industrial applications of bioprocess to produce microbial carotenoids generally employ genetically modified strains, being hyper-producing strains that had been manipulated to maximize carotenoids production. Among the several strategies to increase overall yield in a microbial carotenoids bioprocess, metabolic engineering for the yeast carotenoids producers in an interesting research area.
The microbial production of carotenoids involved several steps:

i) Selection of the appropriate substrate. The raw materials utilized might or not be pretreated depending on the fermentative capacity of the microorganism and the type of enzymes produced.

ii) Bioreactor. The bioreactor configuration and operational variables are crucial for the maximum yields of the process.

iii) Downstream processing. Production of intracellular pigments is limited by the complexity of "downstream" processing [123]. Cell disruption is a critical step to recover intracellular compounds and it affects recovery yield and carotenoids properties $[124,125]$.

Carotenoid produced by yeasts as Rhodotorula spp. and Phaffia rhodozyma are synthesized and remained into the cells, therefore extraction processes are needed to recover the product of interest resulting in high costs of production [119]. The developing of recovery techniques of carotenoids has been an issue of study. Some techniques used for carotenoid extraction are shown in Table 3. These techniques used for cell disruption allow obtain the carotenoid formed into the cells. Actually, the downstream processing is the major challenge to recover intracellular pigments; many investigations have been performed to concerning the recovery of products; an ideal recovery process must be in non-time-consuming, low cost and high yields.

Table 2 Bioreactors employed to carotenoid production with yeasts

\begin{tabular}{lccc}
\hline Authors & Bioreactor & Yeast & Yield (carotenoid) \\
\hline Malisorn and Suntornsuk [70] & $3 \mathrm{~L}$ stirred tank & R. glutinis & $201 \mu \mathrm{g} \mathrm{L}^{-1}\left(24 \mathrm{~h}^{2}\right.$ \\
Ungureanu et al., [118] & $3.7 \mathrm{~L}$ stirred tank & R. rubra & $710 \mathrm{\mu g} \mathrm{L}^{-1}$ \\
Park et al., [122] & $5 \mathrm{~L}$ stirred tank & R. glutinis & $266.1 \mathrm{mg} \mathrm{g}^{-1}$ of biomass \\
Luna Flores et al., [43] & $3 \mathrm{~L}$ stirred tank & X. dendrorhus & $8798.6 \mathrm{mg} \mathrm{g}^{-1}$ of biomass \\
\hline
\end{tabular}




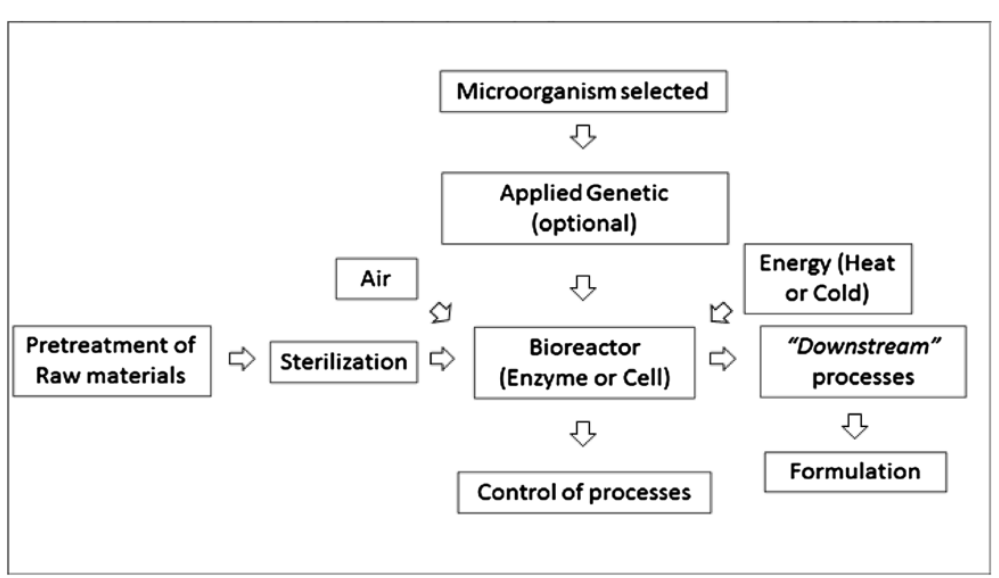

Figure 2 General scheme of biotechnological processes for carotenoids production.

The development of biotechnological processes to produce carotenoid has recently increased because it is a reliable method to obtain carotenoids. Several patents related to microbial production of carotenoids have been registered worldwide (Table 4).

\section{Metabolic engineering to production of carotenoids in yeasts}

A strategy to reduce the costs of production is the obtaining of hyper-producer strains. Efficient techniques have been described to obtaining of mutant strains [120]. A simple technique is the random and selection mutagenesis through the color. For this techniques have been used chemical (Ethyl methane sulfonate, 1-methyl-3-nitroguanidine or antymicine A) and physical methods (UV light, gamma radiation).

Metabolic engineering is the improvement of cellular properties through the modification of specific biochemical reactions or the introduction of new ones, with the use of recombinant DNA technology [122]. Nowadays, the engineering in non-carotenogenic microorganisms for carotenoid production is a very useful tool. Metabolic engineering of microorganisms to produce higher levels of important molecules is a great possibility to improve public health through biotechnology [133]. The selection of appropriate microorganism is the first step in biotechnological processes, which could be undergone to mutagenesis to improve the strains and subsequently the production of metabolites [134].

Many authors have reported the application of metabolic engineering in yeasts, such as Sacharomyces cerevisiae [135-139] and Candida utilis [140,141]. The yeasts afore mentioned were modified successfully to production of carotenoids as: $\beta$-carotene, lycopene or Astaxanthin by the insertion of carotenogenic genes from Erwinia uredovora, Agrobacterium aurantiacum or Xanthophyllomyces dendrorhus. These yeasts are very useful in food industries, they are considered generally recognized as safe organisms by FDA (US) [142]. Bacteria such as Escherichia coli [143] have been described as microorganisms engineered to produce carotenoid, however S. cerevisiae is considered as a safe yeast and presents many advantages as easy genetic manipulation with established host-vector systems. Although naturally the yeast $S$. cerevisiae does not produce carotenoids, but it produces geranylgeranyl diphosphate, and if this yeast is integrated with the two main

Table 3 Extraction of carotenoids using different techniques of cell disruption

\begin{tabular}{|c|c|c|c|}
\hline Authors & Disruption technique & Yeast & Yield (carotenoid) \\
\hline \multirow[t]{3}{*}{ Michelon et al., [123] } & Freezing and maceration with diatomaceous earth & P. rhodozyma & $93.13 \mu \mathrm{g} \mathrm{g}^{-1}$ of biomass \\
\hline & Freezing and DMSO & P. rhodozyma & $155.72 \mu \mathrm{g} \mathrm{g}^{-1}$ of biomass \\
\hline & Enzymatic lysis and ultrasonic waves & P. rhodozyma & $163.12 \mu \mathrm{g} \mathrm{g}^{-1}$ of biomass \\
\hline Aksu and Eren [38] & Bead grinder & R. glutinis & $125 \mathrm{mg} \mathrm{L}^{-1}$ of medium \\
\hline Park et al., [122] & Freeze-dried & R. glutinis & $266.1 \mu^{-1} \mathrm{~g}^{-1}$ of biomass \\
\hline Valduga et al., [119] & Freezing in liquid $\mathrm{N}_{2}$ and maceration & S. salmonicolor & $590.4 \mu \mathrm{g} \mathrm{L}^{-1}$ of medium \\
\hline Taskin et al., [118] & DMSO, acetone and petroleum ether & R. glutinis & $92 \mathrm{mg} \mathrm{L}^{-1}$ of medium \\
\hline Gu et al., [58] & $\mathrm{HCl}$ and acetone & Rhodotobacter sphaeroides & $4790 \mathrm{\mu g} \mathrm{g}^{-1}$ of biomass \\
\hline Buzzini et al., [78] & DMSO, acetone and petroleum ether & Rhodotorula graminis & $803.2 \mu \mathrm{g} \mathrm{g}^{-1}$ of biomass \\
\hline
\end{tabular}


Table 4 Current patents of microbial carotenoid production

\begin{tabular}{|c|c|c|c|}
\hline Inventor & Title & Country & Year \\
\hline Bailey et al., [126] & Carotenoid production in oleaginous yeasts and molds & MX & 2012 \\
\hline Mohamed et al., [127] & Biological production of Zeaxanthin and carotenoid biosynthesis control & US & 2013 \\
\hline Martin et al.,[128] & Efficient astaxanthin production strains derived from Haematococcus pluvalis & US & 2013 \\
\hline Ruiz et al., [129] & Novel strain of Lactobacillus plantarum for the production of carotenoids & GRM & 2010 \\
\hline Yu et al., [130] & Method for preparing and extracting carotenoid from microbial thalli & US & 2012 \\
\hline Nanjun-Daswamy., [131] & Fermentation process to produce natural carotenoids and carotenoid-enriched feed products. & US & 2012 \\
\hline Bailey R et al., [132] & Production of carotenoid in oleaginous yeast and fungi & US & 2010 \\
\hline
\end{tabular}

carotenogenic genes, phytoene synthase $(\operatorname{crtYB})$ and phyotene desaturase (ctrI), from Xanthophyllomyces dendrorhous could produce carotenoids [144]. Being a characterized its genetic system, physiology and regulatory networks [133], this yeast is appropriate to be engineered to produce carotenoids.

An early attempt to produce $\beta$-carotene in $S$. cerevisiae was performed by Yamano et al. [145] using bacterial genes. The researching was successful in engineering the yeast to obtain $\beta$-carotene; nevertheless the level produced was low (103 $\mu \mathrm{g} / \mathrm{g}$ dry wt.). Verwaal et al., [140] studied the expression of carotenogenic genes which encode a bifunctional phytoene synthase and lycopene synthase from $X$. dendrorhus. The concentration of $\beta$-carotene obtained was $5.9 \mathrm{mg} \mathrm{g}^{-1}$ (dry wt.), with the improved strain. Also to produce $\beta$-carotene S. cerevisiae has been engineered for production of other carotenoids. Ukibe et al. [139] used genes encode to phytoene synthase (CrtI) and bifunctional phytoene synthase/lycopene cylase (CrtYB) from $X$. dendrorhus.

On the other hand, Pichia pastoris is other noncarotenogenic yeast that has also been studied to production of carotenoids, and it is able to grow in organic materials. Araya-Garay et al. [141] designed and constructed two plasmids containing the genes encoding lycopene and $\beta$-carotene. The results showed that obtained a recombinant strain, producer of lycopene and $\beta$-carotene reaching $1.141 \mu \mathrm{g}$ and $339 \mu \mathrm{g}$ per gram of dry biomass, respectively.

\section{Conclusions}

Carotenoids are important molecules that improve foods quality due to their high nutritional value. For these reasons, carotenoid application as colorants has increased the interest of industries and scientists to develop lowcost process for carotenoid production. Biotechnological production mainly provides economics advantages over synthetic or extracted plant carotenoids. Yeast carotenoids have advantages such a high growth rate, decreasing the production time at industrial scale. On the other hand the use of low-cost substrates as agro-industrial wastes diminish the processes costs, and giving an alternative to the use of these wastes contributing to reduce environmental contamination. More research focused on the use of agro-industrial wastes, high carotenoids-producing yeast through metabolic engineering strategies, bioreactor design and control strategies for microbial carotenoids production are necessary to cover the worldwide demand by poultry, cosmetic, food, feed, beverages and others industries.

This review aims to show an overview on the biotechnological processes for carotenoid production, and the possibility to produce them at low costs, high yields and to reduce processing time. The knowledge about these processes is critical to improve and create new technologies in the production of microbial carotenoids.

\section{Competing interests}

Authors declare that they have no competing interests.

\section{Authors' contributions}

LCMG contributed with the paper writing, data researching and the changes requested by the referees. AMZ supported the paper writing, data researching and revised the changes made to this paper. JCMS and CNAG revised and approved the changes made, and also with data researching and formatted the review. All authors read and approved the final manuscript.

\section{Acknowledgements}

Authors thank for the economic support provided by CONACYT (National Council of Science and Technology).

\section{Author details}

${ }^{1}$ Food Science and Technology Program, School of Chemistry, Universidad Autónoma de Coahuila, Saltillo, Mexico. ${ }^{2}$ Chemical Engineering Department, School of Chemistry, Universidad Autónoma de Coahuila, Saltillo, Mexico. ${ }^{3}$ Group of Bioprocesses, Food Research Department, School of Chemistry, Universidad Autónoma de Coahuila, Saltillo, Mexico.

Received: 3 July 2013 Accepted: 19 December 2013

Published: 21 January 2014

\section{References}

1. Maldonade IR, Rodriguez-Amaya DB, Scamparini ARP: Carotenoids of yeasts isolated from Brazilian ecosystem. Food Chem 2008, 107(Suppl 1):145-150.

2. Britton G, Hornero-Méndez D: Carotenoids and colour in fruit and vegetables. In Phytochemistry of fruit and vegetables. Edited by Tomás-Barberán FA, Robins RJ. Oxford: Clarendon Press; 1997:11-27.

3. Johnson EA, Schroeder WA: Microbial carotenoids. In A Fiecher. Volume 53 Edited by Springer-Verlage. Heidelberg: Adv Biochl Eng Biotech; 1995:119-178.

4. Fraser PF, Bramley PM: The biosynthesis and nutritional uses of carotenoids. Prog Lipid Res 2004, 43:228-265. 
5. Bauernfeind JC: Carotenoids, colorants and Vitamin A precursors. In Technological and nutritional applications. New York: Academic Press; 1981:938

6. Borowitzka MA: Micro-algae as sources of fine chemicals. Microbiol Sci 1986, 3:372-375

7. BCC Research: The global market for carotenoids. 2011 [http://www. bccresearch.com/market-research/food-and-beverage/carotenoids-globalmarket-fod025d.html].

8. Bhosale P, Bernstein PS: Microbial Xanthophylls. Appl Microbiol Biotechnol 2005, 68:445-455.

9. Britton $\mathrm{G}$, Liaaen-Jensen S, Pfander H: Isolation and analysis. In Carotenoids, Volume 1a. Stuttgart, Germany: Birkhaüser Verlag Basel; 1995.

10. Sakaki H, Nakanishi T, Tada A, Miki W, Komemushi S: Activation of torularhodin production by Rhodotorula glutinis using weak white light irradiation. J Biosci Bioeng 2001, 92:294-297.

11. Sakaki H, Nochide H, Komemushi S, Miki W: Effect of active oxygen species on the productivity of torularhodin by Rhodotorula glutinis. J Biosc Bioeng 2002, 93(Suppl 21):338-340.

12. Johnson EA, Lewis M: Astaxanthin formation by the yeast Phaffia rhodozyma. J Gen Microbiol 1979, 115:173-183.

13. Reynders MB, Rawlings DE, Harrison STL: Studies on the growth, modeling and pigment production by the yeast Phaffia rhodozyma during fed-batch cultivation. Biotech Lett 1996, 18(Suppl 6):649-654.

14. Hannibal L, Lorquin J, D' Ortoli NA, García N, Chaintreuil C, Masson-Boivin C, Dreyfus B, Giraud E: Isolation and characterization of canthaxanthin biosynthesis genes from the photosynthetic bacterium Bradyrhizobium sp. Strain ORS278. J Bacteriol 2000, 182:3850-3853.

15. Ribeiro $B$, Barreto $D$, Coelho M: Tecnological aspects of $\beta$-carotene production. Food Biop Tech 2011, 4:693-701.

16. Rucker RB, Suttie JW, McCormick DB, Machlin LJ: Handbook of Vitamins. 3rd edition. New York: Marcel Dekker; 2001:1-600.

17. Niizu PY: Fontes de carotenóides importantes para saúde human Dissertação, PhD thesis. UNICAMP, Faculdade de Engenharia de Alimentos, Ciência dos Alimentos; 2003

18. Della Penna D, Pogson BJ: Vitamin synthesis in plants: tocopherols and carotenoids. Annu Rev Plant Biol 2006, 57:711-738.

19. Packer L, Hiramatsu M, Yoshikawa T: Antioxidants Food Supplements in Human Health. Amsterdam, Netherlands: Elsevier; 1999.

20. Rodríguez-Amaya DB, Kimura M, Godoy HT, Amaya Farfan J: Updated Brazilian database on food carotenoids: factors affecting carotenoid composition. J Food Comp Anal 2008, 21:445-463.

21. Palozza P, Serini S, Di Nicuolo F, Piccioni E, Calviello G: Prooxidant effects of $\beta$-carotene in cultured cells. Mol AspMed 2003, 24:353-362.

22. Krinsky NI, Johnson EJ: Carotenoid actions and their relation to health and disease. Mol Asp Med 2005, 26:459-516.

23. Tapiero H, Townsend DM, Tew KD: The role of carotenoids in the prevention of human pathologies. Biomed Pharm 2004, 58:100-110.

24. Voutilainen S, Nurmi T, Mursu J, Rissanen TH: Carotenoids and cardiovascular health. Amer J Clin Nut 2006, 83:1265-1271.

25. Dufossé L, Galaup P, Yaron A, Arad SM, Blanc P, Murphy KNC, Ravishankar $G A$ : Microorganisms and microalgae as sources of pigments for food use: a scientific oddity or an industrial reality? Trends Food Sci Tech 2005, 16:389-406

26. Coulson J: Miscellaneous naturally occurring coloring materials for foodstuff. In Developments in food colour. Edited by Walford J. London: Applied Science Publishers; 1980:189-218.

27. Counsell J: Some synthetic carotenoids as food colours. In Developments in food colour. Edited by Walford J. London: Applied Science; 1980:151-187.

28. De Haan A, Burke R, Bont J: Microbial production of food colorants. Med Fac Landbouww Rijisuniv Gent 1991, 56:1655-1660.

29. Papaioannou EH, Liakopoulou-Kyriakides M: Substrate contribution on carotenoids production in Blakeslea trispora cultivations. Food Bioprod Process 2010, 88:306-311.

30. Almeida ERA, Cerda-Olmedo E: Gene expression in the regulation of carotene biosynthesis in Phycomyces. Curr Genet 2008, 53:129-137.

31. Cerda-Olmedo E: Phycomyces and the biology of light and color. FEMS Microbiol Rev 2001, 25(5):503-312.

32. Tinoi J, Rakariyatham N, Deming RL: Simplex optimization of carotenoid production by Rhodotorula glutinis using hydrolyzed mung bean waste flour as substrate. Process Biochem 2005, 40:2551-2557.

33. Perrier V, Dubreucq E, Galzy P: Fatty acid and carotenoid composition of Rhodotorula strains. Arch Microbiol 1995, 164:173-179.
34. Davoli P, Mierau V, Weber RWS: Carotenoids and fatty acids in red yeasts Sporobolomyces roseus and Rhodotorula glutinis. Appl Biochem Microbiol 2004, 40:392-397.

35. Borowitzka MA, Huisman JM, Osborn A: Culture of the astaxanthinproducing green alga Haematococcus pluvialis effects of nutrients on growth and cell type. J App Phycol 1991, 22:253-263.

36. Kobayashi M, Kakizono T, Nagai S: Astaxanthin production by a green alga, Haematococcus pluvialis accompanied with morphological changes in acetate media. J Ferm Bioeng 1991, 71:335-339.

37. Sarada R, Usha T, Ravishankar GA: Influence of stress on astaxanthin production in Haematococcus pluvialis grown under different culture conditions. Process Biochem 2002, 37:623.

38. Aksu Z, Eren AT: Production of carotenoids by isolated yeast of Rhodotorula glutinis. Biochem Eng J 2007, 35:107-113.

39. Nasri-Nasravadi MR, Razavi SH: Use of response surface methodology in a fed-batch process optimization of tricarboxylic acid cycle intermediates to achieve high levels of canthaxanthin from Dietzia natronolimnaea HS1. J Biosci Bioeng 2010, 109(4):361-368.

40. Del Campo JA, García-González M: Outdoor cultivation of microalgae for carotenoid production: current state and perspectives. Appl Microbiol Biotech 2007, 74:1163-1174.

41. Costa I, Martelli HL, De Silva IM, Pomeroy D: Production of $\beta$-carotene by Rhodotorula Strain. Biotech Lett 1987, 9(Suppl 5):373-375.

42. Squina FM, Yamashita F, Pereira JL, Mercadante AZ: Production of carotenoids by Rhodotorula glutinis in culture medium supplemented with sugar cane juice. Food Biotech 2002, 16(Suppl 3):227-235.

43. Luna Flores CH, Ramirez Cordova JJ, Pelayo Ortiz C, Femat R, Herrera Lopez EJ: Batch and Fed-batch modeling of carotenoids production by Xanthophyllomyces dendrorhous using yucca fillifera date juice as substrate. Biochem Eng J 2010, 53(Suppl 1):131-136.

44. Saenge C, Cheirsilp B, Suksaroge T, Bourtoom T: Potential use of oleaginous red yeast Rhodotorula glutinis for the bioconversion of crude glycerol from biodiesel plant to lipids and carotenoids. Proc Biochem 2011, 46(Suppl 1):210-218.

45. Libkind $\mathrm{D}$, van Brook M: Biomass and carotenoid pigment production by Patagonian native yeasts. World J Microbiol Biotechnol 2006, 22:687-692.

46. Frengova G, Beshkova D: Carotenoids from Rhodotorula and Phaffia: yeasts of biotechnological importance. J Ind Microbiol Biotechnol 2009, 36:163-180

47. Simpson KL, Nakayama TOM, Chichester CO: Biosynthesis of yeast carotenoids. J Bacterio/ 1964, 88:1688-1694.

48. Goodwin TW: Biosynthesis of carotenoids. In The biochemistry of the carotenoids, Volume 1. Edited by Goodwin TW. London: Chapman and Hall; 1980:33-76.

49. Moliné M, Flores MR, Libkind D, del Carmen DM, Farías ME, van Broock M: Photoprotection by carotenoid pigments in the yeast Rhodotorula mucilaginosa: the role of torularhodin. Photochem Photobiol Sci 2010 9:1145-1151.

50. Buzzini $P$, Innocenti $M$, Turchetti B, Libkind D, van Broock M, Mulinacci N Carotenoid profiles of yeasts belonging to the genera Rhodotorula, Rhodosporidium, Sporobolomyces, and Sporidiobolus. Can J Microbiol 2007, 53:1024-1031

51. Fang TJ, Chiou TY: Batch cultivation and astaxanthin production by to mutant of the net yeast Phaffia rhodozyma NCHU-FS501. J Ind Microbiol 1996, 16:175-181.

52. Yamane $Y$, Higashida K, Nakashimada $Y$, Kakizono T, Nishio N: Influence of oxygen and glucose on primary metabolism and astaxanthin production by Phaffia rhodozyma in batch and fed-batch cultures: kinetic and stoichiometric analysis. Appl Environ Microbiol 1997, 63:4471-4478.

53. Ramírez J, Gutierrez H, Gschaedler A: Optimization of astaxanthin production by Phaffia rhodozyma through factorial design and response surface methodology. J Biotechnol 2001, 88:259-268.

54. Fang TJ, Wang JM: Extractability of astaxanthin in a mixed culture of a carotenoid over-producing mutant of Xanthophyllomyces dendrorhous and Bacillus circulans in two-stage batch fermentation. Process Biochem 2002, 37:1235-1245.

55. Del Río E, Acién FG, García-Malea MC, Rivas J, Molina E, Guerrero MG: Efficient one-step production of astaxanthin by the microalgae Haematococcus pluvialis in continuous culture. Bio- technol Bioeng 2005, 91(7):808-815 
56. Orosa M, Franqueira D, Cid A, Abalde J: Analysis and enhancement of astaxanthin accumulation in Haematococcus pluvialis. Bioresour Technol 2005, 95(3):373-378.

57. Marcoleta A, Niklitschek M, Wozniak A, Lozano C, Alcaíno J, Baeza M, Cifuentes $V$ : Glucose and ethanol-dependent transcriptional regulation of the astaxanthin: biosynthesis pathway in Xanthophyllomyces dendrorhous. BCM Microbiol 2011, 11:190.

58. Gu WL, An GH, Johnson EA: Ethanol increases carotenoid production in Phaffia rhodozyma. J Ind Microbiol Biotechnol 1997, 19:114-117.

59. Goodwin TW: Biosynthesis of carotenoids: an overview. In Methods in enzymology carotenoids. Part B. Metabolism, genetic and biosynthesis, Volume 214. Edited by Parker L. San Diego: Academic; 1993:330-340.

60. Raja R, Haemaiswarya S, Rengasamy R: Exploitation of Dunalliella for B-carotene production. Appl Microbiol Biotechnol 2007, 74:517-523.

61. Tada M, Shiroishi M: Mechanism of photoregulated carotenogenesis in Rhodotorula minuta. V. Photoinduction of 3-hydroxy-3-methy glutaryl coenzyme A reductase. Plant Cell Physiol 1982, 23:615-621.

62. Weeks OB, Saleh FK, Wirahadikusumah M, Berry RA: Photoregulated carotenoid biosynthesis in non-photosynthetic microorganisms. Pure Appl Chem 1973, 35:63-80.

63. Mathews MM, Krinsky NI: The relationship between carotenoid pigment and resistance to radiation in non-photosynthetic bacteria. Photochem Photobiol 1965, 4:813-817.

64. Yen $\mathrm{H}$, Zhang Z: Enacement of cell growth rate by light irradiation in the cultivation of Rhodotorula glutinis. Biores Tech 2011, 102(Suppl 19):9279-9281.

65. Martin A, Lu C, Patel T: Growth parameters for the yeast Rhodotorula rubra grown in peat extracts. J Ferment Bioeng 1993, 76:321-325.

66. Longo E, Siero C, Velazquez JB, Calo P, Cansado J, Villa TG: Astaxanthin production from Phaffia rhodozyma. Biotechnol Forum Eur 1992, 9:565-567.

67. Vijayalakshmi G, Shobha B, Vanajakshi V, Divakar S, Manohar B: Response surface methodology for optimization of growth parameters for the production of carotenoids by a mutant strain of Rhodotorula gracilis. Eur Food Res Technol 2001, 213:234-239.

68. Aksu Z, Eren AT: Carotenoids production by the yeast Rhodotorula mucilaginosa: use of agricultural wastes as a carbon source. Process Biochem 2005, 40:2985-2991.

69. Bhosale P, Gadre RV: Optimization of carotenoid production from hyperproducing Rhodotorula glutinis mutant 32 by a factorial approach. Lett Appl Microbiol 2001, 33:12-16.

70. Malisorn C, Suntornsuk W: Optimization of $\beta$-carotene production by Rhodotorula glutinis DM28 in fermented radish brine. BioresTech 2008, 99:2281-2287.

71. Hayman EP, Yokoyama H, Chichester CO, Simpson KL: Carotenoid biosynthesis in Rhodotorula glutinis. J Bacteriol 1974, 120:1339-1343.

72. Frengova G, Simova E, Pavlova K, Beshkova D, Grigorova D: Formation of carotenoids by Rhodotorula glutinis in whey ultrafiltrate. Biotechnol Bioeng 1994, 44:888-894.

73. Frengova Gl, Simova ED, Beshkova DM: Carotenoid production by lactosenegative yeasts co-cultivated with lactic acid bacteria in whey ultrafiltrate. Z Naturforsch 2003, 58:562-567.

74. Hu ZC, Zeng YG, Wang Z, Shen YC: pH control strategy in astaxanthin fermentation bioprocess by Xanthophyllomyces dendrorhous. Enzyme Microb Technol 2006, 39:586-590.

75. Ni H, Chen Q, Ruan H, Yang Y, Li L, Wu G, Hu Y, He G: Studies on optimization of nitrogen sources for astaxanthin production by Phaffia rhodozyma. J Zhejiang Univ Sci B 2007, 8:365-370.

76. Simova ED, Frengova Gl, Beshkova DM: Synthesis of carotenoids by Rhodotorula rubra GED8 co-cultivated with yogurt starter cultures in whey ultrafiltrate. J Ind Microbiol Biotechnol 2004, 31:115-121.

77. Zheng YG, Hu ZC, Wang Z, Shen YC: Large-scale production of astaxanthin by Xanthophyllomyces dendrorhous. Food Bioprod Process 2006, 84:164-166.

78. Buzzini P: Batch and fed-batch carotenoid production by Rhodotorula glutinis-Debaryomyces castelli co-cultures in corn syrup. J Appl Microbiol 2001, 90:843-847.

79. Frengova G, Simova E, Beshkova D: Use of whey ultrafiltrate as a substrate for production of carotenoids by the yeast Rhodotorula rubra. Appl Biochem Biotechnol 2004, 112:133-141.

80. Kusdiyantini E, Gaudin P, Goma G, Blanc PJ: Growth kinetics and astaxanthin production of Phaffia rhodozyma on glycerol as a carbon source during batch fermentation. Biotech Lett 1998, 20:929-934.
81. Moriel DG, Chociai MB, Machado IMP, Fontana JD, BonWm TMB: Effect of feeding methods on the astaxanthin production by Phaffia rhodozyma in fed-batch process. Braz Arch Biol Technol 2005, 48:397-401.

82. Ramirez J, Obledo N, Arellano M, Herrera E: Astaxanthin production by Phaffia rhodozyma in a fed-batch culture using a low cost medium feeding. E-Gnosis 2006, 4:1-9.

83. Vazquez M, Martin AM: Mathematical model for Phaffia rhodozyma growth using peat hydrolysates as substrate. J Sci Food Agric 1998, 76:481-487.

84. Bhosale P, Gadre RV: Manipulation of temperature and illumination conditions for enhanced $\beta$-carotene production by mutant 32 of Rhodotorula glutinis. Lett Appl Microbiol 2002, 34:349-353.

85. Chan HY, Ho KP: Growth and carotenoid production by $\mathrm{pH}$-stat cultures of Phaffia rhodozyma. Biotechnol Lett 1999, 21:953-958.

86. Hu ZC, Zheng YG, Wang Z, Shen YC: Production of astaxanthin by Xanthophyllomyces dendrorhous ZJUT46 with fed- batch fermentation in 2.0 m3 fermentor. Food Technol Biotech 2007, 45:209-212.

87. Simova ED, Frengova Gl, Beshkova DM: Effect of aeration on the production of carotenoid pigments by Rhodotorula rubra, Lactocacillus casei subsp. casei co-cultures in whey ultrafiltrate. Z Naturforsch 2003, 58:225-229.

88. Komemushi S, Sakaki H, Yokoyama H, Fujita T: Effect of barium and other metals on the growth of a D-lactic acid assimilating yeast Rhodotorula glutinis N21. J Antibact Antifung Agt 1994, 22:583-587.

89. Buzzini P, Martini A, Gaetani M, Turchetti B, Pagnoni UM, Davoli P. Optimization of carotenoid production by Rhodotorula graminis DBVPG 7021 as a function of trace element concentration by means of response surface analysis. Enz Microb Technol 2005, 36:687-692.

90. Kim SJ, Kim GJ, Park DH, Ryu YW: High-level production of astaxanthin by fed-batch culture of mutant strain Phaffia rhodozyma AJ-6-1. J Microbiol Biotechnol 2003, 13:175-181.

91. Goodwin TW: Carotenoids in fungi and non-photosynthetic bacteria. Prog Ind Microbiol 1972, 11:29-88.

92. Latha BV, Jeevaratnam K, Murali HS, Manja KS: Influence of growth factors on carotenoid pigmentation of Rhodotorula glutinis DER-PDY from natural source. Indian J Biotechnol 2005, 4:353-357.

93. Somashekar D, Joseph R: Inverse relationship between carotenoid and lipid formation in Rhodotorula gracilis according to the $\mathrm{C} / \mathrm{N}$ ratio of the growth medium. World J Microbiol Biotechnol 2000, 16:491-493.

94. Kim JH, Kang SW, Kim SW, Chang HI: High-level production of astaxanthin by Xanthophyllomyces dendrorhous mutant $\mathrm{JH} 1$ using statistical experimental designs. Biosci Biotechnol Biochem 2005, 69:1743-1748.

95. Sun N, Lee S, Song KB: Characterization of a carotenoid- hyperproducing yeast mutant isolated by low-dose gamma irradiation. Int J Food Microbiol 2004, 94:263-267.

96. Parajo JC, Santos V, Vazguez M: Optimization of carotenoid production by Phaffia rhodozyma cells grown on xylose. Process Biochem 1998, 2:181-187.

97. Polulyakh OV, Podoprigova Ol, Eliseev SA, Ershov Y, Bykhovsky WY, Dmitrovski AA: Biosynthesis of torulene and torularhodin in the yeast Phaffia rhodozyma. Prikl Biokhim Microbiol 1991, 27:541-545.

98. Wang SL, Zhang $X$, Zhang H, Lin K: Effects of some additives on the growth and carotenoids content of Rhodotorula. Food Sci Technol 2001 2:20-21.

99. Meyer P, Du Preez J: Astaxanthin production by a Phaffia rhodozyma mutant on grape juice. World J Microbiol Biotechnol 1994, 10:178-183.

100. Buzzini P, Martin A: Production of carotenoids by strains of Rhodotorula glutinis cultured in raw materials of agroindustrial origin. Biores Technol 1999, 71:41-44.

101. Buzzini P: An optimization study of carotenoid production by Rhodotorula glutinis DBVPG 3853 from substrates containing concentrated rectified grape must as the sole carbohydrate source. $J$ Ind Microbiol Biotechnol 2000, 24:41-45.

102. Vazquez M, Martin AM: Optimization of Phaffia rhodozyma continuous culture through response surface methodology. Biotechnol Bioeng 1998, 57:314-320

103. Martin A, Acheampong E, Patel T, Chornet E: Study of growth parameters for Phaffia rhodozyma cultivated in peat hydrolysates. Appl Biochem Biotechnol 1993, 37:235-241.

104. Tinoi J, Rakariyatham N, Deming RL: Utilization of mustard waste isolated for improved production of astaxanthin by Xanthophyllomyces dendrohous. J Ind Microbiol Biotechnol 2006, 33:309-314. 
105. Cruz JM, Parajo JC: Improved astaxanthin production by Xanthophyllomyces dendrorhous growing on enzymatic wood hydrolysates containing glucose and cellobiose. Food Chem 1998, 63:479-484.

106. Parajo JC, Santos V, Vazquez M: Production of carotenoids by Phaffia rhodozyma growing on media made from hemicellulosic hydrolysates of eucalyptus globulus wood. Biotechnol Bioeng 1998, 59:501-506.

107. Fontana JD, Chocial MB, Baron M, Guimaraes MF, Maraschin M, Ulhoa C, Florencio JA, Bonfim TM: Astaxanthinogenesis in the yeast Phaffia rhodozyma. Optimization of low-cost culture media and yeast cell wall lysis. Appl Biochem Biotechnol 1997, 63:305-314.

108. Sguina FM, Yamashita F, Pereira JL, Mercadante AZ: Production of carotenoids by Rhodotorula rubra and Rhodotorula glutinis in culture medium supplemented with sugar cane juice. Food Biotechnol 2002, 16:227-235

109. An G, Jang $B$, Cho M: Cultivation of the carotenoid-hyper- producing mutant $2 \mathrm{~A} 2 \mathrm{n}$ of the red yeast Xanthophyllomyces dendrorhous (Phaffia rhodozyma) with molasses. J Biosci Bioeng 2001, 92:121-125.

110. Bhosale P, Gadre RV: $\beta$-carotene production in sugarcane molasses by a Rhodotorula glutinis mutant. J Ind Microbiol Biotechnol 2001, 26:327-332.

111. Kesava SS, An GH, Kim CH, Rhee SK, Choi ES: An industrial medium for improved production of carotenoids from a mutant strain of Phaffia rhodozyma. Bioprocess Biosyst Eng 1998, 19:165-170.

112. Zalashko M: Biotechnology of milk whey processing. Moscow: Science Press; 1990.

113. Demain A, Phaff HJ, Kurtzzmanu C: The industrial importance of yeasts. In The yeasts. A taxonomic study, Volume 2. 4th edition. Edited by Kurtzmann C. Fell J Amsterdam: Elsevier; 1998:13-19.

114. Bredberg K, Christiansson M, Stenberg B, Holst O: Biotechnological processes for recycling of rubber products. In Biopolymers. Willey-VCH Verlag GmbH \& Co. KGaA; 2005.

115. Panesar PS, Kennedy JF: Biotechnological approaches for the value addition of whey. Cri Rev Biotech 2012, 32(4):327-348.

116. Marova I, Carnecka M, Halienova A, Certik M, Dvorakova T, Haronikova A: Use of several waste substrates for carotenoid-rich yeast biomass production. J Env Manag 2011, 95:338-342.

117. Nasrabadi M, Razavi S: Optimization of $\beta$-carotene production by a mutant of the lactose-positive yeast Rhodotorula achenorium from whey ultrafiltrate. Food Sci Biotech 2011, 20:445-454.

118. Taskin M, Sisman T, Erdal S, Basaran EK: Use of waste chicken feathers as peptone for production of carotenoids in submerged culture of Rhodotorula glutinis MT-5. Eur Food Res Technol 2011, 233:657-665.

119. Valduga E, Tatsch $P$, Vanzo L, Rauber F, Di Luccio M, Treichel H: Assessment of hydrolysis of cheese whey and use of hydrolysate for bioproduction of carotenoids by Sporidiobolus salmonicolor CBS 2636. J Sci Food Agric 2009, 89:1060-1065.

120. Malisorn C, Suntornsuk W: Improved $\beta$-carotene production of Rhodotorula glutinis in fermented radish brine by continuous cultivation. Biochem Eng J 2009, 43:27-32.

121. Hu Z, Zhang X, Wu Z, Qi H, Wang Z: Export of intracellular Monascus pigments by two-stage microbial fermentation in nonionic surfactant micelle aqueous solution. J Biotech 2012, 31(Suppl 162):202-209.

122. Park $P$, Kim $E$, Chu K: Chemical disruption of yeast cells for the isolation of carotenoid pigments. Sep Purif Tech 2007, 53:148-152.

123. Michelon M, Matos de Borba T, Ruan de Silva R, Veiga Burkert CA, de Medeiros Burkert JF: Extraction of carotenoids from Phaffia rhodozyma: A comparison between different techniques of cell disruption. Food Sci Biotech 2012, 21:1-8.

124. Becerra M, Belmonte ER, Cerdán ME, Siso MIG: Extraction of intra cell proteins from Kluyveromyces lactis. Food Technol Biotech 2007, 39:135-139.

125. Buxadó JA, Heynngnezz LE, Juiz AG, Tamayo G, Lima IR, Marshalleck HD, Mola EL: Scale-up of processes to isolate the misstargeted rBm86 protein from Pichia pastoris. Afr J Biotech 2004, 11:599-605.

126. Bailey R, Madden KT, Trueheart J: Production of carotenoids in oleaginous yeast and fungi. USA: MICROBIA, INC; 2012

127. Mohamed I, Mearns AS, Fraser K, Hodgson R: Biological production of zeaxanthin and carotenoid biosynthesis control. 2013.

128. Martin L, Irina O, Baldomero FC, Angeles MV, Albrecht W, Bernhard G, Wilhlem J: Efficient Astaxanthin production strains derived from Haematococcus pluvalis. DE: Cognis IP Management GmbH; 2013.
129. Ruiz BJL, Garrido FJ, Horenero MD, Maldonado BA, Caballero GB: Nueva cepa de Lactobacillus plantarum para la producción de carotenoides. GER: WO 2010/142828 A1; 2010

130. Yu L, Wang H, Lu M, He M, He F: Method for preparing and extracting from microbial thalli. US; 2012:CN102732049.

131. Nanjun-Daswamy A: Fermentation process to produce natural carotenoids and carotend-enriched feed products. 2012. PCT/US2011/ 057835; US.

132. Bailey R, Madden KT, Trueheart J: Production of carotenoids in oleaginous yeast and fungi. C12Q1/68; 2010, US.

133. Ye VM, Bhatia SK: Pathway engineering strategies for production of beneficial carotenoids in microbial hosts. Biotech Let 2012, 34:1405-1414.

134. Palágyi ZS, Ferenczy L, Vágvölgyi C: Carbon-source assimilation pattern of the astaxanthin-producing yeast Phaffia rhodozyma. World J Microbiol Biotechnol 2001, 17:95-97.

135. Ungureanu C, Ferdes $M$, Chirvase AA: Torularhodin biosynthesis and extraction by yeast cells of Rhodotorula rubra. Rev Chim 2012, 63:316-318.

136. Stephanopoulos G: Metabolic fluxes and metabolic engineering. Metab Eng 1998, 1:1-11.

137. Maury J, Asadollahi MA, Moller K, Clark A, Nielsen J: Microbial isoprenoid production: an example of green chemistry through metabolic engineering. Adv Biochem Eng Biotechnol 2005, 100:19-51.

138. Lange N, Steinbüchel A: $\beta$-carotene production by Saccharomyces cerevisiae with regard to plasmid stability and culture media. Appl Microbiol Biotechnol 2011, 91:1611-1622

139. Bhataya A, Schmidt-Dannert C, Lee PC: Metabolic engineering of Pichia pastoris X-33 for lycopene production. Process Biochem 2009, 44:10951102.

140. Miura Y, Kondo K, Saito T, Shimada H, Fraser PD, Misawa N: Production of carotenoids lycopene, $\beta$-carotene and astaxanthin in food yeast Candida utilis. Appl Environ Microbiol 1998, 64:1226-1229.

141. Misawa N, Shimada H: Metabolic engineering for the production of carotenoids in non-carotenogenic bacteria and yeasts. J Biotechnol 1998 59:169-181

142. Araya-Garay JM, Ageitos JM, Vallejo JA, Veiga-Crespo P, Sánchez Perez A Villa TG: Construction of a novel Pichia pastoris strain for production of xanthophylls. AMB exp 2012, 2:24.

143. Kim SW, Kim JB, Jung WH, Kim JH, Jung JK: Over- production of betacarotene from metabolically engineered Escherichia coli. Biotechnol Lett 2006, 28:897-904

144. Veerwaal R, Wang J, Meijnen J-P, Visser H, Sandmann G, van den Berg JA, van Ooyen A: High-level production of beta-carotene in Saccharomyces cereviseae by successive transformation with carotenogenic genes from Xanthophyllomyces dendrorhous. Appl Environ Microbiol 2007, 73:43424350.

145. Yamano $S$, Ishii $T$, Nakagawa $M$, Ikenaga $H$, Misawa N: Metabolic engineering for production of beta-carotene and lycopene in Saccharomyces cerevisiae. Biosci Biotechnol Biochem 1994, 58:1112-1114.

doi:10.1186/1475-2859-13-12

Cite this article as: Mata-Gómez et al:: Biotechnological production of carotenoids by yeasts: an overview. Microbial Cell Factories 2014 13:12.

\section{Submit your next manuscript to BioMed Central and take full advantage of:}

- Convenient online submission

- Thorough peer review

- No space constraints or color figure charges

- Immediate publication on acceptance

- Inclusion in PubMed, CAS, Scopus and Google Scholar

- Research which is freely available for redistribution 